\title{
Challenges and Future Directions to Evaluating the Association Between Prenatal Exposure to Endocrine-Disrupting Chemicals and Childhood Obesity
}

\author{
Megan E. Romano • David A. Savitz • Joseph M. Braun
}

Published online: 15 March 2014

(C) Springer International Publishing AG 2014

\begin{abstract}
Obesity is an increasing public health threat worldwide. However, there has been insufficient research addressing the obesogenic potential of prenatal exposure to environmental endocrine-disrupting chemicals, largely due to complexities in the design, analysis, and interpretation of such studies. This review describes relevant biological mechanisms, addresses current challenges for investigators, presents potential strategies for overcoming them, and identifies areas where further development is required to improve future research. Special considerations for exposure assessment, outcome heterogeneity, and complex confounding structures are described.
\end{abstract}

Keywords Obesogen · Endocrine disruptor · Epidemiology · EDC $\cdot$ Childhood obesity $\cdot$ Obesity risk $\cdot$ Environment

\section{Introduction}

Obesity is one of the greatest public health threats in the USA and a pressing international public health problem. Approximately 78 million US adults are obese ( $36 \%$ ) and the WHO estimates that 2.3 billion people on this planet will be overweight or obese by 2015 [1,2]. More troubling is the increasing prevalence of obesity among US children, rising from $14 \%$ in $1999-2000$ to $19 \%$ in 2009-2010 [2]. Obesity during childhood is associated with increased long-

\footnotetext{
M. E. Romano $(\varangle) \cdot$ D. A. Savitz · J. M. Braun

Department of Epidemiology, Brown University,

Box G-S121-2, Providence, RI 02912, USA

e-mail: megan_romano@brown.edu

D. A. Savitz

e-mail: david_savitz@brown.edu

J. M. Braun

e-mail: joseph_braun1@brown.edu
}

term risk of type 2 diabetes, cardiovascular disease, metabolic syndrome, non-alcoholic fatty liver disease, infertility, cancer, and other chronic diseases [3••], resulting in substantial financial and personal costs [4]. Because there are few effective interventions that lead to stable weight reduction once a person becomes obese or overweight, prevention is a public health priority $[5,6]$.

While caloric imbalance resulting from excess food consumption and inadequate physical activity are the primary proximal determinants of the obesity epidemic, there is growing evidence that the in utero environment programs the fetus for obesity risk. Gestation represents a discrete period of high susceptibility to obesogens, since epigenetic programming and other molecular mechanisms during fetal development may permanently affect adipogenesis, metabolism, and appetite across the lifespan. Prenatal exposures that increase the risk of obesity have been labeled 'obesogens,' and some experimental and epidemiological studies have suggested that these exposures cause obesity independently or mediated by the traditional risk factors.

An adverse fetal environment can lead to enduring functional and structural changes to the body that increase obesity and chronic disease risk via programming of neuroendocrine systems involved in energy metabolism [7]. The endocrine system-including gonadal hormones, cortisol, and thyroid hormones - play important roles in fetal growth, metabolism, and adipogenesis [8]. Though other chemicals may influence obesity, environmental endocrine-disrupting chemicals (EDCs) are of particular concern because of their ability to alter endogenous hormone signaling and metabolism, which may adversely affect adipogenesis or induce epigenetic or molecular changes that alter hormonally sensitive endpoints such as metabolism, energy homeostasis, or appetite. The developing fetus is particularly sensitive to hormone-like xenobiotics because biologically protective mechanisms (e.g., DNA repair, detoxifying enzymes, and a fully functional 
blood-brain barrier) are incompletely developed in utero [9]. Gestational EDC exposures may ultimately result in irreversible changes, whereas exposure later in life may be reversible or removal of exposure may diminish adverse effects [10]. Likewise, experimental evidence suggests the potential for new and emerging EDCs that may influence adiposity [11]. Epidemiological investigations of prenatal obesogens present special challenges during the design, analysis, and interpretation of studies. These include exposure assessment, outcome heterogeneity, and complex confounding structures. This review provides an overview of potential mechanisms of obesogen action and focuses on these challenges, presents potential strategies for addressing these issues, and highlights areas where additional development is necessary to improve future research.

\section{Potential Mechanisms of Environmental Obesogens}

The intrauterine environment affects multiple biological mechanisms influencing early growth, metabolism, and appetite, and fetal adaptations to an adverse intrauterine environment may catalyze enduring changes in glucoseinsulin homeostasis [12] and increased adiposity [13••]. Perturbations to maternal nutrition can influence later health outcomes, and both insufficient fetal growth (birth weight below the 10th percentile) and excessive growth (birth weight above the 90th percentile) are associated with dyslipidemia, type 2 diabetes, obesity, and metabolic syndrome during adulthood [13••]. As evidenced by a 5month famine during 1944-1945 in a previously wellnourished population (The Dutch Hunger Winter), a short period of severe maternal nutritional restriction adversely affects offspring at multiple stages of gestation [12]. Exposure to famine during early gestation increased risk of higher lipids and obesity in adulthood, whereas exposure late in gestation decreased glucose tolerance [12]. Fetal growth restriction can catalyze postnatal 'catch-up' growth and 'adiposity rebound,' resulting in greater body weight during childhood [14]. A recent retrospective cohort study of members of Kaiser Permanente found that infants born after intrauterine growth restriction (IUGR) grew faster during the first year, though no differences in body mass index (BMI) were obvious. However, during adolescence, those who had experienced IUGR had significant increases in waist circumference $(67.0$ vs. $65.3 \mathrm{~cm})$ and insulin level $(15.2$ vs. $11.0 \mu \mathrm{U} / \mathrm{ml})$ with decreased adiponectin levels $(9.0$ vs. $12.0 \mu \mathrm{g} / \mathrm{ml})$ [14].

Gestational environmental EDC exposure may adversely influence neuroendocrine circuits, hormonal regulation of adipose tissue development, and regulatory systems controlling body weight [15]. Studies suggest that these biological systems are sensitive to prenatal EDC exposure, related to subsequent development of obesity or metabolic disorders, and may be amenable to epidemiological study (Table 1). Rigorous mechanistic examination of the action of environmental obesogens requires epidemiological studies with in-depth analysis of energy expenditure, molecular phenotypes, adipose distribution, and epigenetics, among other potential mechanistic pathways [16]. Since the study of obesogens remains in its infancy, relevant biological mechanisms and appropriate measures of each are unknown, necessitating epidemiological studies with banked biospecimens or the development of new prospective cohorts with appropriate measures. Below, we briefly describe three potential mechanism of obesogen action: appetite regulation, adipocyte function and differentiation, and changes to the fetal epigenome. Grün and Blumberg offer a full review of proposed mechanisms [17].

\section{Metabolic Regulation}

EDCs may interfere with food intake and energy expenditure by disrupting adipocytokines, such as leptin and adiponectin. For both children and adults, leptin and adiponectin are critical regulators of body energy balance, glucose and lipid metabolism, and insulin resistance, but elevations in leptin may be the result of different biological mechanisms depending on the life stage [18-22]. Primarily produced by adipocytes, but also by the placenta, leptin regulates appetite and bodyweight by conveying satiety signals to hypothalamic receptors, resulting in central regulation of both food intake and energy expenditure [18]. For the fetus, leptin signals that existing fat depots are sufficient and additional storage of fat is unnecessary [23]. Experimental evidence suggests that leptin may upregulate 11- $\beta$-hydroxysteroid dehydrogenase-2 (11- $\beta$-HSD-2), shielding the developing fetus from the growth-inhibiting properties of glucocorticoids [24]. Macrosomic offspring of diabetic mothers have elevated leptin [25], whereas low concentrations of placental and cord leptin [26] and increased cord blood leptin promoter DNA methylation are observed among small for gestational age infants [27], suggesting that both too much and too little leptin reaching the fetus results in non-optimal fetal growth phenotypes that subsequently increase long-term obesity risk [13••]. Caloric restriction decreases leptin, whereas overeating elevates leptin [28]. In a healthy adult, leptin is proportional to body fat, delivers the satiety signal to the hypothalamus, and acts peripherally to reduce subsequent energy storage by signaling to the pancreas to decrease insulin secretion. This suggests that leptin may not be a causal agent when measured in childhood or adulthood, but rather a marker of obesity. However, when this system is de-coupled, leptin resistance in the pancreas ensues and insulin increases [29], making abnormally high leptin a marker of metabolic dysfunction among adults. 
Table 1 Summary of biological mechanisms for obesogenic action of endocrine-disrupting chemicals and potential endpoints for epidemiologic study

\begin{tabular}{|c|c|}
\hline Obesogenic mechanisms & Example endpoints \\
\hline $\begin{array}{l}\text { - Increased food intake, decreased energy expenditure, disrupted satiety } \\
\text { signal, and increased bodyweight }\end{array}$ & - Adipocytokines (e.g., serum leptin) \\
\hline $\begin{array}{l}\text { - Non-optimal size at birth with adverse effect on lifelong growth trajectory } \\
\text { and body weight/composition }\end{array}$ & - Birth anthropometrics, adipose distribution (e.g., skinfold thickness) \\
\hline - Modified disposition of adipocytes affecting body composition & - Body fat distribution (e.g., dual-energy x-ray absorptiometry) \\
\hline $\begin{array}{l}\text { - Disturbed metabolism and transport of endogenous hormones resulting in } \\
\text { excess body weight }\end{array}$ & • Gonadal hormones (e.g., estrogen) \\
\hline - Dysfunction of glucose/lipid homeostasis or insulin resistance & - Insulin (e.g., oral glucose tolerance test) \\
\hline $\begin{array}{l}\text { - Changes in epigenetic regulation of adipogenesis, appetite and satiety } \\
\text { signaling, and glucose/lipid metabolism }\end{array}$ & $\begin{array}{l}\text { - DNA methylation, histone modification, or expression of genes involved } \\
\text { in metabolism or adipogenesis }\end{array}$ \\
\hline
\end{tabular}

Adiponectin is also a critical metabolic regulator secreted exclusively by adipose tissue in non-pregnant individuals [18]. Some evidence suggests that the placenta synthesizes adiponectin during pregnancy $[30,31]$. Circulating adiponectin is low in individuals with obesity or insulin resistance [32]. Among non-pregnant adults, adiponectin promotes insulin sensitivity. Pregnant women with gestational diabetes or prepregnancy obesity tend to have low adiponectin levels and deliver large infants [33], whereas women who are leaner prior to pregnancy have high adiponectin levels [34•].

Gestational EDC exposure may have long-lasting impacts on adipocytokines. In a Danish birth cohort, women with the highest gestational perfluorooctanoate (PFOA) exposure had a threefold increase in risk for overweight/obesity at age 20 years [relative risk $=3.1 ; 95 \%$ CI 1.4-6.9] compared with women with the lowest exposure. Consistent with this, increasing maternal PFOA exposure was associated with increased serum leptin and decreased adiponectin at 20 years of age [35].

\section{Adipocyte Function and Differentiation}

EDCs may directly bind to nuclear hormone receptors or impact the metabolism/transport of endogenous hormones. Nuclear hormone receptors and their endogenous ligands, which include gonadal hormones, insulin, and glucocorticoids, regulate adipocyte function, proliferation, and differentiation [10, 36••]. Experimental studies suggest a role for sex steroids in regulating both adipocyte size and number [37], influencing disposition and remodeling of adipose tissue $[38,39]$, and counteracting the promotion of lipid accumulation by insulin [17]. However, the estrogen-body weight relationship changes over the lifecourse. Elevated estrogen levels have obesogenic effects during fetal development and antiobesogenic effects during adulthood, especially in postmenopausal women [15, 37]. During development, exposure to estrogenic substances leads to increased bodyweight and adipocyte number [9], as evidenced by experimental studies of gestational exposure to the estrogenic chemical, bisphenol A
(BPA) $[40,41]$. An association between prenatal BPA exposure and increased waist circumference and BMI at 4 years of age has been observed in humans [42]. However, others observed that greater prenatal BPA exposure was associated with reduced BMI among girls but not boys at 9 years of age [43].

The peroxisome proliferator-activated receptors (PPAR $\alpha$, PPAR $\delta$, and PPAR $\gamma$ ) are nuclear hormone receptors that regulate many facets of lipid and glucose metabolism. In particular, inappropriate PPAR $\gamma$ activation leads to increased adipocyte differentiation, energy storage, obesity, and insulin resistance [10]. Lipid metabolism and glucose homeostasis are intricately connected and dysfunction in either causes progressive metabolic signaling across tissues, ultimately affecting adiposity and appetite. Although insulin's primary function is to promote glucose uptake, it is also essential for breaking down triglycerides. Deficits in neuronal insulin receptors are associated with overeating and obesity, and metabolic compensation between muscle and fat due to glucose intolerance results when insulin signaling is disrupted [44]. Fetal hyperinsulinemia prompted by a maternal diabetic state (either gestational or pregestational) increases adiposity of the fetus, and increased maternal and fetal glucose levels promote unnecessary nutrient storage [8]. EDCs may cause subclinical fluctuations in maternal-fetal insulin and/or glucose that similarly promote adiposity to a lesser degree than a maternal diabetic state. Additionally, some EDCs, such as phthalates and perfluoroalkyl substances, are known PPAR $\gamma$ agonists, which stimulate proliferation of adipocytes and are associated with increased waist circumference [45-47].

The glucocorticoid pathway is also susceptible to the influence of EDCs. Glucocorticoids (cortisol in humans) are steroid hormones produced by the adrenal cortex, which regulate multiple processes necessary for the maintenance of blood glucose [48]. In experimental models, exposure to exogenous glucocorticoids in late gestation leads to glucose intolerance persisting into adulthood [49]. Glucocorticoid receptors (GRs) are expressed throughout fetal tissues and the placenta [48], and excess intrauterine glucocorticoid exposure reduces the quantity of GRs in the hypothalamus, degrading 
the negative feedback satiety signal sent to the hypothalamicpituitary-adrenal (HPA) axis [50]. Local placental expression of 11- $\beta$-HSD-2 prevents excessive glucocorticoid passage from the mother to fetus and cortisol-induced growth inhibition [51]. Phthalates inhibit $11-\beta$-HSD-2 activity in animal and in vitro models, suggesting that exposure to this class of chemicals could have obesogenic activity by increasing prenatal glucocorticoid levels [52].

\section{Epigenetic Modifications}

Recently, attention has turned toward understanding how environmental chemicals might alter epigenetic programming, which involves heritable changes to gene expression without modification of the underlying DNA sequence [53]. Epigenetic changes during development, such as DNA methylation or histone modification, to genes involved in metabolism or adipogenesis have long-lasting impacts on metabolic systems $[54,55]$ and may elicit transgenerational effects [56]. Some, but not all, experimental studies suggest that gestational exposure to estrogenic EDCs (e.g., BPA) can induce epigenetic programming associated with obesity $[57,58]$. Multiple EDCs are capable of modifying patterns of DNA methylation, including diethylstilbestrol [59], tetrachlorodibenzo-pdioxin [60], and BPA [61]. As high-throughput technology for measuring epigenetic marks has become cheaper, epigenetic studies are becoming more common and increasingly feasible to implement. Currently, the greatest challenges to incorporating epigenetics into epidemiologic studies are identifying the most informative and accessible tissues to study, as epigenetic changes can vary across cell types and time, and the clinical implications of observed changes are largely undetermined $[62,63 \bullet]$.

\section{Epidemiological Considerations for Measurement of Obesogen Mechanisms}

Interdisciplinary collaboration among laboratory scientists, epidemiologists, and clinicians is needed to identify biological mechanisms relevant to prenatal programming of obesity and to develop valid and reliable methods for epidemiological studies. The choice of biomarkers or measures should consider their comparability to animal studies and efforts should be made to identify endpoints that can be 'anchored' across species. Clinical relevance of these biomarkers in obesity development should be considered since some markers can be measured before obesity develops (e.g., cord blood leptin levels) and their role in adult disease is not fully understood. Below, we describe the key methodological points of concern for the study of EDCs as obesogens, including challenges in exposure assessment, identification of the most scientifically relevant endpoint, and the handling of potentially complex confounders (Table 2).

\section{Exposure Measurement}

Accurate exposure assessment is universally necessary for environmental epidemiology studies, but the choice, timing, and collection of biospecimens and attention to pregnancyinduced pharmacokinetic changes are particularly important in the study of prenatal obesogens. For many chemicals, there are multiple potential biological matrices for assessing prenatal exposure (maternal blood, cord blood, urine, hair, etc.). Thus, the choice of matrix should consider logistical challenges, including sample contamination and biases arising from compliance with biospecimen collection. Sampling schemes must be thoughtfully designed to capture the etiologically relevant window of exposure, such that exposure assessment covers potentially sensitive periods of vulnerability to chemical obesogens and reflects the totality of human exposure to multiple environmental chemicals $[64,65]$. Timing of sample collection for persistent pollutants may be more flexible, whereas non-persistent chemicals that are metabolized within hours or days may require repeated assessment or collection of integrated matrices [64]. It is often necessary to account for urine dilution or plasma volume expansion (PVE) since confounding may arise if PVE or urine dilution is related to both the exposure biomarker and outcome under study [66]. Collecting multiple matrices may be advantageous since an alternative matrix, less influenced by PVE or urine dilution (e.g., hair, meconium [67], shed deciduous teeth [68]) allows for comparison of environmental chemical levels across matrices. Alternatively, investigators may conduct sensitivity analyses stratified by factors associated with PVE or urine dilution that are most relevant to the study population [66]. More broadly, this is an area where development of exposure assessment methods geared toward the complexities of pregnancy is necessary to improve studies of gestational exposures.

The influence of body composition on blood EDC concentrations can be quite complex, particularly in the case when the chemical of interest is lipophilic. Inverse associations between lipophilic compounds, such as polychlorinated biphenyls (PCBs), measured in maternal blood, and offspring body weight or BMI may be explained by a weight gaininduced dilution of serum PCB levels during pregnancy [69, 70]. Normal physiological changes during pregnancy are one potential source of bias, but sub-clinical/clinical disease may alter both fetal growth and the metabolism or excretion of environmental chemicals. Investigators often employ lipid standardization to account for the difference in blood concentration of the chemical of interest and that in the relevant physiologic compartment (i.e., adipose tissue). Commonly, 
Table 2 Key methodological challenges and considerations in the design, analysis, and interpretation of studies of prenatal exposure to endocrinedisrupting chemicals and childhood obesity

\begin{tabular}{|c|c|}
\hline Key methodological challenges & Considerations \\
\hline \multirow[t]{3}{*}{ Exposure measurement } & - Choice, timing, and collection of biological matrix for chemical measurement \\
\hline & $\begin{array}{l}\text { - Physiologic changes during pregnancy affecting fetal growth and chemical absorption, metabolism, distribution, } \\
\text { and elimination }\end{array}$ \\
\hline & - Joint or cumulative effects of exposures and co-pollutant confounding \\
\hline \multirow[t]{4}{*}{ Choice of endpoint } & - Heterogeneous etiologies of obesity require careful choice of outcome for study \\
\hline & - Availability of equipment, cost, sample size, specialized assessment techniques, and training of personnel \\
\hline & - Participant burden, invasiveness of outcome measurement, and age-appropriate expectations of participants \\
\hline & - Timing of outcome measurement \\
\hline \multirow[t]{4}{*}{ Confounding and effect modification } & - Time-varying exposures, outcomes, and confounders \\
\hline & - Mediation of prenatal effects by postnatal phenotype \\
\hline & - Complex confounding structure for diet and physical activity \\
\hline & - Effect modification by sex \\
\hline
\end{tabular}

the ratio of the exposure of interest to blood lipids is utilized to estimate the true adipose tissue concentration [71]. However, improper lipid adjustment can substantially bias effect estimates [71, 72]. In choosing how to treat lipids in a statistical model, it is essential to thoughtfully evaluate the presumed causal structure of the relationship under study, gauge relevant biological mechanisms, consider the media in which the lipophilic compound was measured, assess the implications of laboratory analytic technique, and address any assumptions required by the specific statistical model being used [72]. In many circumstances, the treatment of lipids as a separate covariate in the model is the least biased [72]. Despite advancements, this is an area in which active development of rigorous methods is warranted.

Identification of the most relevant chemical exposures is inherently difficult because humans are exposed to complex chemical mixtures every day. Examination of the effect of chemical mixtures requires clear delineation of potential sources, understanding of pharmacokinetics, knowledge of interactions among substances, and an ability to account for common modes of action across chemicals [73]. Acknowledgment of this complexity and advances in both statistical and exposure assessment methodology will assist in moving away from explorations of single exposures to more rigorous multipollutant models. However, this remains an area of active development within the field of environmental epidemiology [74].

\section{Defining the Operational Outcome of Interest}

While obesity is a fairly straightforward conceptual outcome, the heterogeneous nature of this disorder requires understanding of metabolic profiles and adipose distribution in choosing an operational definition for obesity in a particular study. Both healthy and unhealthy metabolic profiles are observed among obese individuals [75], suggesting the potential for different etiologies and consequences, making the choice of endpoint in studies of prenatal obesogens critical. Assessment of caloric intake and energy expenditure is necessary for studies of obesogens examining metabolic efficiency. However, in order to elucidate the complex interplay among potential obesogen targets, investigators must move beyond opportunistic examination of anthropometric measures and turn their attention toward more refined measurement of body composition, potential confounders, metabolic sensors and programming, hormonal axes, and hunger and satiety [15].

Birth anthropometrics are tempting endpoints as they have been correlated with childhood obesity [76]. However, they may not capture important metabolic differences and their association with long-term risk of chronic disease may vary across populations and ethnicities [77•]. It has been suggested that more sensitive measures of obesity than birth size and total body fat may be required to predict later complications such as metabolic syndrome [78, 79]. Body fat distribution and metrics that allow the differentiation of subcutaneous versus visceral or truncal versus gluteal fat should be utilized based upon the ultimate endpoint of interest [80]. When the goal is to assess body composition, a pragmatic choice must often be made to balance the aims of the research against logistic aspects of outcome assessment including availability of equipment, cost and sample size, and participant burden or invasiveness of the measurement technique [81]. Fortunately, there are multiple techniques for measuring body composition in infancy/childhood to suit a variety of research settings and scientific needs [77•]. Magnetic resonance imaging (MRI) [82], dual-energy x-ray absorptiometry (DXA) [83], and air-displacement plethysmography (e.g., PeaPod®) [84], are robust and well-validated methods for assessing body composition but require specialized equipment and considerable 
financial investment [77•]. Additionally, MRI or DXA measurements require sustained periods of stillness from the participant and investigators must carefully consider whether this is an ageappropriate expectation for children in the study [85]. Airdisplacement plethysmography measures body density and calculates the proportion of body fat using Archimedes' principle; however, the PeaPod $\AA$ only accommodate body weights up to $8 \mathrm{~kg}$, which is only typically useful until 4-6 months after delivery $[77 \cdot, 86]$. Simpler methods such as skinfold thicknesses and bioelectrical impedance analysis (BIA) can be highly informative for assessing body composition and offer pragmatic advantages in many research settings [77•, 86]. Skinfold thickness has been successfully validated against DXA for measurement of body fat in infants and newborns [87]. For older children, BIA can be very useful, whereas it is not readily applied during infancy due to the difficulty in appropriately placing electrodes and the requirement that muscles are relaxed [77•].

Understanding metabolic phenotypes of obesity is an increasing research priority, but, to date, adipocytokines, hormones, and molecular endpoints have been under-utilized in epidemiologic studies of obesogens. Such measurements are necessary to advance mechanistic understanding of the metabolic underpinnings of obesity. Assays are available to measure leptin and adiponectin in cord and maternal blood; however, the etiologically relevant time period remains unclear, making the appropriate timing of sample collection difficult. Assessment of changes in placental leptin, leptin receptor, and adiponectin receptor messenger RNA (mRNA) have also been used to describe adipocytokine profiles during pregnancy [88], and these may prove most relevant to assessing fetal effects.

Maternal and fetal glucose, lipids or fatty acids, insulin and insulin-like growth factors, cortisol and its binding protein, as well as gonadal and thyroid hormones should be further explored as important mechanistic endpoints for the study of obesity. Optimizing such endpoints for research is not a simple task, though. Meaningful measurement of insulin in young populations can be challenging, because no universally accepted standards of insulin resistance have been developed due to a lack of sufficiently sized cohorts to describe normal variability among children [89]. Highly valid measurements of insulin sensitivity (e.g., euglycemic hyperinsulinemic clamp, frequently sampled intravenous glucose tolerance test) are costly and require high participant burden due to the necessity of serial blood samples. The oral glucose tolerance test has a lower cost and burden. However, references for juvenile populations are not validated; fasting insulin is not always well-correlated with insulin resistance in children and is not optimal for examining peripheral insulin sensitivity $[89,90]$.

Salivary cortisol is used to measure HPA axis function. Levels rise early after waking and fall over the course of the day, requiring collection of three to six timed saliva samples for accurate characterization of diurnal rhythm [91]. Certain features of cortisol profiles are associated with coronary calcification in adults [92] and elevated maternal cortisol levels during pregnancy are associated with decreased birth weight [93]. Biases may arise when examining associations between obesogen exposure and salivary biomarkers because the timing of saliva collection predicts cortisol levels and factors affecting compliance with saliva sample collection may covary with factors predicting obesogen exposure. Despite these difficulties, a fuller understanding of hormonal and molecular endpoints is necessary for elucidating obesogen mechanisms and identifying windows of susceptibility.

\section{Special Issues of Confounding and Potential Effect Modification}

Though not specific to the study of environmental obesogens, the time-varying nature of EDC exposure, confounders, and outcomes can increase analytic complexity. Additionally, prenatal effects may be mediated by a postnatal phenotype if gestational exposure leads to increased appetite during childhood and a subsequent rise in BMI. This highlights the necessity of clearly defining the exposure and outcome under study as well as refraining from the use of cross-sectional designs. Statistical methods are available to address the complexity of time-varying confounders and mediators $[94,95]$.

Because several known risk factors for obesity (e.g., diet and physical activity) are directly or indirectly associated with EDC exposure or factors involved in EDC measurement, it is essential to control for such confounders during statistical analysis. However, difficulty ensues when measurement of

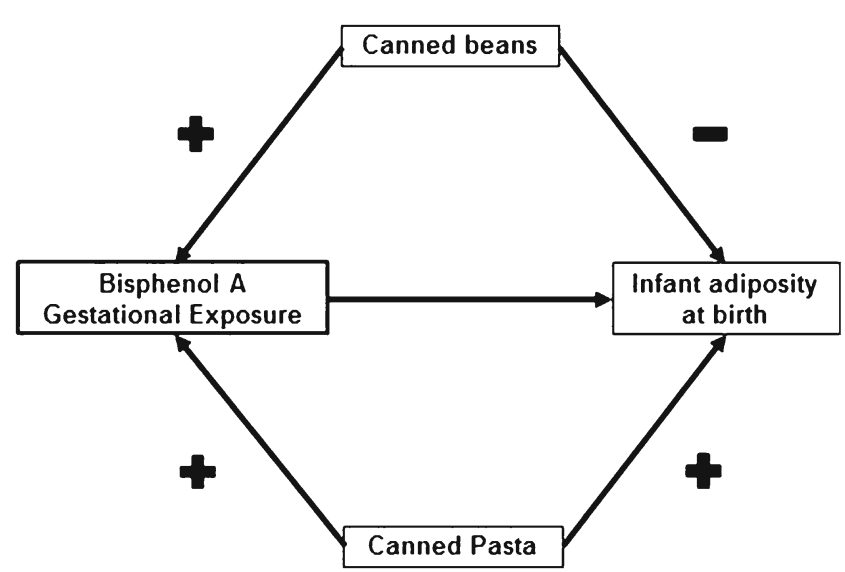

Fig. 1 Potential differences in the direction of confounding based on nutrient quality and source in the investigation of the effect of gestational bisphenol A (BPA) exposure on infant adiposity. $(+)$ denotes a positive association between the potential confounder and either BPA exposure or infant adiposity such that as the value of the confounder increases, the value of the exposure or outcome increases as well; (-) denotes a negative or inverse association between the potential confounder and infant adiposity, such that as the value of confounder increases, the value of the outcome decreases 
exposure and confounder becomes entangled. A high-calorie/fat 'Western diet' is also high in lipophilic environmental chemicals [96]. However, traditional assumptions about the associations among diet, chemical exposure, and obesity may be overly simplistic. For instance, positive associations between urinary BPA levels and BMI in cross-sectional analyses may be due to residual confounding from unmeasured dietary sources of BPA exposure that are also important determinants of adiposity (e.g., soda or canned foods) [96, 97]. However, some canned foods are a source of micronutrients and fiber (e.g., beans) while others are less nutrient dense (e.g., pasta) [98]. Thus, the direction of confounding will depend on the dietary source of BPA exposure and its association with obesity (Fig. 1). Typical food frequency questionnaires or 24-h recalls are designed to assess macro- or micronutrient intake, but do not capture the nuances of nutrient source. Thus, these instruments may mis-specify dietary confounding. Future questionnaires must be detailed enough to capture both sources of chemical exposures (i.e., food packaging) and nutrition.

Assessment of physical activity is equally complex and pivotal. While physical activity is not directly related to EDC exposure in the general population, excretion and metabolism of EDCs may be influenced by greater physical activity. In occupational settings, blood concentration of trichloroethylene and urinary excretion of related metabolites doubled when workers engaged in rigorous physical activity ( $50 \mathrm{~W}$ workload) during exposure via inhalation, though similar activity after exposure had less impact [99]. Intense physical activity and greater muscle mass are associated with increases in serum and urinary creatinine $[100,101]$. Frequent physical activity may result in greater urinary creatinine or higher rates of excretion of persistent chemicals, thereby confounding the EDC-obesity association in ways that are not easily predictable. Physical activity can be challenging to quantify, though recent advances in accelerometers, pedometers, and heart rate monitors make detailed physical activity assessment more accessible and affordable for epidemiological studies [102].

Finally, the potential for effect modification of the EDCobesogen association cannot be overlooked. Sex-specific differences in body fat distribution in humans suggest that the physiology of adipose tissue is sexually dimorphic and related to endogenous gonadal hormones, including estradiol and testosterone [103]. Observation of sex-specific effects of BPA [43] and other EDCs highlight the need for larger studies to examine potential effect modification by infant or child sex when studying obesogenic effects of EDCs since many existing cohorts may not have sufficient statistical power to do so.

\section{Conclusions}

Obesity will continue to be one of the greatest public health threats to this generation of children. Because there are few effective interventions to reverse obesity and there is evidence that gestational EDC exposure increases obesity risk [36••], there is a compelling need to conduct targeted research aimed at closing current knowledge gaps. In order to advance epidemiologic knowledge, additional methods development is needed to improve exposure and outcome assessment as well as to improve measurement and statistical control of confounding. Investigators must move beyond opportunistic assessment of environmental exposures and simplistic measures of obesity in order to advance knowledge of obesogenic mechanisms. Research efforts must be geared toward novel, carefully designed studies, primarily aimed at examining potential obesogens. If chemical obesogens are identified, prevention and elimination of chemical exposures during windows of susceptible development must become a public health priority in addition to the current focus on intervention and weight reduction during childhood.

Acknowledgments This research was supported by grant R00 ES020346 from the National Institute of Environmental Health Sciences. The authors have no conflicts of interest to disclose.

\section{Compliance with Ethics Guidelines}

Conflict of Interest M.E. Romano declares no conflicts of interest. D.A. Savitz declares no conflicts of interest.

J.M. Braun declares no conflicts of interest.

Human and Animal Rights and Informed Consent This article does not contain any studies with human or animal subjects performed by any of the authors.

\section{References}

Papers of particular interest, published recently, have been highlighted as:

- Of importance

•• Of major importance

1. Global status report on noncommunicable diseases 2010. Geneva: World Health Organization; 2010.

2. Ogden CL, Carroll MD, Kit BK, Flegal KM. Prevalence of obesity in the United States, 2009-2010. NCHS Data Brief. 2012;(82):1-8.

3.• Kelsey MM, Zaepfel A, Bjornstad P, Nadeau KJ. Age-related consequences of childhood obesity. Gerontology. 2014. doi:10. 1159/000356023. This review provides a concise description of known and proposed associations between childhood obesity and long-term morbidities.

4. Barker DJ. The developmental origins of adult disease. J Am Coll Nutr. 2004;23(6 Suppl):588S-95S.

5. Singh AS, Mulder C, Twisk JW, van Mechelen W, Chinapaw MJ. Tracking of childhood overweight into adulthood: a systematic review of the literature. Obes Rev Off J Int Assoc Study Obes. 2008;9(5):474-88. doi:10.1111/j.1467-789X.2008.00475.x.

6. Waters E, de Silva-Sanigorski A, Hall BJ, Brown T, Campbell KJ, Gao Y, et al. Interventions for preventing obesity in children. 
Cochrane Database Syst Rev. 2011;12, CD001871. doi:10.1002/ 14651858.CD001871.pub3.

7. Barker DJP. Developmental origins of chronic disease. Public Health. 2012;126(3):185-9. doi:10.1016/j.puhe.2011.11.014.

8. Blackburn ST. Maternal, fetal, \& neonatal physiology: a clinical perspective. 3rd ed. St. Louis: Saunders Elsevier; 2007.

9. Newbold RR, Padilla-Banks E, Jefferson WN. Environmental estrogens and obesity. Mol Cell Endocrinol. 2009;304(1-2):84 9. doi:10.1016/j.mce.2009.02.024.

10. Grün F, Blumberg B. Perturbed nuclear receptor signaling by environmental obesogens as emerging factors in the obesity crisis. Rev Endocr Metab Disord. 2007;8(2):161-71. doi:10.1007/ s11154-007-9049-x.

11. Patisaul HB, Roberts SC, Mabrey N, McCaffrey KA, Gear RB, Braun J, et al. Accumulation and endocrine disrupting effects of the flame retardant mixture Firemaster(R) 550 in rats: an exploratory assessment. J Biochem Mol Toxicol. 2013;27(2):124-36. doi:10.1002/jbt.21439.

12. Painter RC, Roseboom TJ, Bleker OP. Prenatal exposure to the Dutch famine and disease in later life: an overview. Reprod Toxicol. 2005;20(3):345-52. doi:10.1016/j.reprotox. 2005.04.005.

13.• Ornoy A. Prenatal origin of obesity and their complications: gestational diabetes, maternal overweight and the paradoxical effects of fetal growth restriction and macrosomia. Reprod Toxicol. 2011;32(2):205-12. doi:10.1016/j.reprotox.2011.05.002. This review provides an overview of hypothalamic programming and describes how insulin resistance, fetal hyperleptinemia, and epigenetic modification may lead to adverse long-term metabolic consequences and obesity.

14. Crume TL, Scherzinger A, Stamm E, McDuffie R, Bischoff KJ, Hamman RF, et al. The Long-term impact of intrauterine growth restriction in a diverse US cohort of children: the EPOCH study. Obesity (Silver Spring). 2014;22(2):608-15. doi:10.1002/oby. 20565.

15. Heindel JJ, vom Saal FS. Role of nutrition and environmental endocrine disrupting chemicals during the perinatal period on the aetiology of obesity. Mol Cell Endocrinol. 2009;304(1-2):90-6. doi:10.1016/j.mce.2009.02.025.

16. Grün F, Blumberg B. Minireview: the case for obesogens. Mol Endocrinol. 2009;23(8):1127-34. doi:10.1210/me.2008-0485.

17. Grün F, Blumberg B. Endocrine disrupters as obesogens. Mol Cell Endocrinol. 2009;304(1-2):19-29. doi:10.1016/j.mce.2009.02.018.

18. Koerner A, Kratzsch J, Kiess W. Adipocytokines: leptin-the classical, resistin-the controversical, adiponectin-the promising, and more to come. Best Pract Res Clin Endocrinol Metab. 2005;19(4): 525-46. doi:10.1016/j.beem.2005.07.008.

19. Ahlsson F, Diderholm B, Ewald U, Jonsson B, Forslund A, Stridsberg $\mathrm{M}$, et al. Adipokines and their relation to maternal energy substrate production, insulin resistance and fetal size. Eur J Obstet Gynecol Reprod Biol. 2013;168(1):26-9. doi:10.1016/j. ejogrb.2012.12.009.

20. Soliman AT, Yasin M, Kassem A. Leptin in pediatrics: a hormone from adipocyte that wheels several functions in children. Indian J Endocrinol Metab. 2012;16 Suppl 3:S577-87. doi:10.4103/22308210.105575

21. Huang JS, Lee TA, Lu MC. Prenatal programming of childhood overweight and obesity. Matern Child Health J. 2007;11(5):46173. doi:10.1007/s10995-006-0141-8.

22. Antuna-Puente B, Feve B, Fellahi S, Bastard JP. Adipokines: the missing link between insulin resistance and obesity. Diabetes Metab. 2008;34(1):2-11. doi:10.1016/j.diabet.2007.09.004.

23. Shroff MR, Holzman C, Tian Y, Evans RW, Sikorskii A. Midpregnancy maternal leptin levels, birthweight for gestational age and preterm delivery. Clin Endocrinol (Oxf). 2013;78(4):607-13. doi:10.1111/cen.12029.
24. Stocker C, O'Dowd J, Morton NM, Wargent E, Sennitt MV, Hislop D, et al. Modulation of susceptibility to weight gain and insulin resistance in low birthweight rats by treatment of their mothers with leptin during pregnancy and lactation. Int $\mathrm{J}$ Obes Relat Metab Disord J Int Assoc Study Obes. 2004;28(1):129-36. doi:10.1038/sj.ijo.0802476.

25. Lea RG, Howe D, Hannah LT, Bonneau O, Hunter L, Hoggard N. Placental leptin in normal, diabetic and fetal growth-retarded pregnancies. Mol Hum Reprod. 2000;6(8):763-9.

26. Hauguel-de Mouzon S, Lepercq J, Catalano P. The known and unknown of leptin in pregnancy. Am J Obstet Gynecol. 2006;194(6):1537-45. doi:10.1016/j.ajog.2005.06.064.

27. Lesseur C, Armstrong DA, Paquette AG, Koestler DC, Padbury JF, Marsit CJ. Tissue-specific Leptin promoter DNA methylation is associated with maternal and infant perinatal factors. Mol Cell Endocrinol. 2013;381(1-2):160-7. doi:10.1016/j.mce.2013.07.024.

28. Wang J, Obici S, Morgan K, Barzilai N, Feng Z, Rossetti L. Overfeeding rapidly induces leptin and insulin resistance. Diabetes. 2001;50(12):2786-91.

29. McMillen IC, Edwards LJ, Duffield J, Muhlhausler BS. Regulation of leptin synthesis and secretion before birth: implications for the early programming of adult obesity. Reproduction. 2006;131(3):415-27. doi:10.1530/rep.1.00303.

30. Lappas M, Yee K, Permezel M, Rice GE. Release and regulation of leptin, resistin and adiponectin from human placenta, fetal membranes, and maternal adipose tissue and skeletal muscle from normal and gestational diabetes mellitus-complicated pregnancies. J Endocrinol. 2005;186(3):457-65. doi:10.1677/joe.1.06227.

31. Caminos JE, Nogueiras R, Gallego R, Bravo S, Tovar S, GarcíaCaballero T, et al. Expression and regulation of adiponectin and receptor in human and rat placenta. J Clin Endocrinol Metab. 2005;90(7):4276-86. doi:10.1210/jc.2004-0930.

32. Gil-Campos M, Cañete RR, Gil A. Adiponectin, the missing link in insulin resistance and obesity. Clin Nutr. 2004;23(5):963-74. doi:10.1016/j.clnu.2004.04.010.

33. Atègbo J-M, Grissa O, Yessoufou A, Hichami A, Dramane KL, Moutairou K, et al. Modulation of adipokines and cytokines in gestational diabetes and macrosomia. J Clin Endocrinol Metab. 2006;91(10):4137-43. doi:10.1210/jc.2006-0980.

34. Aye ILMH, Powell TL, Jansson T. Review: adiponectin-the missing link between maternal adiposity, placental transport and fetal growth? Placenta. 2013;34(Suppl):S40-5. doi:10. 1016/j.placenta.2012.11.024. This review describes pregnancyrelated changes in adiponectin and the physiological implications of non-optimal adiponectin for the fetal-placental unit with a focus on fetal growth.

35. Halldorsson TI, Rytter D, Haug LS, Bech BH, Danielsen I, Becher $\mathrm{G}$, et al. Prenatal exposure to perfluorooctanoate and risk of overweight at 20 years of age: a prospective cohort study. Environ Health Perspect. 2012;120(5):668-73. doi:10.1289/ehp. 1104034.

36.• Legler J, Hamers T, van Eck van der Sluijs-van de Bor M, Schoeters G, van der Ven L, Eggesbo M, et al. The OBELIX project: early life exposure to endocrine disruptors and obesity. Am J Clin Nutr. 2011;94(6 Suppl):1933S-8S. doi:10.3945/ajcn.110.001669. The paper delineates the hypotheses of the OBesogenic Endocrine disrupting chemicals: LInking prenatal eXposure to the development of obesity later in life (OBELIX) study (aimed at assessing gestational exposure to EDCs, identifying asscociations between EDC exposure and metabolic disease, and elucidating obesogenic mechanisms of EDCs), and offers a succinct review of known biological mechanisms.

37. Cooke PS, Naaz A. Role of estrogens in adipocyte development and function. Exp Biol Med (Maywood). 2004;229(11):1127-35.

38. Danilovich N, Babu PS, Xing W, Gerdes M, Krishnamurthy H, Sairam MR. Estrogen deficiency, obesity, and skeletal abnormalities 
in follicle-stimulating hormone receptor knockout (FORKO) female mice. Endocrinology. 2000;141(11):4295-308.

39. Murata Y, Robertson KM, Jones ME, Simpson ER. Effect of estrogen deficiency in the male: the ArKO mouse model. Mol Cell Endocrinol. 2002;193(1-2):7-12.

40. Somm E, Schwitzgebel VM, Toulotte A, Cederroth CR, Combescure C, Nef S, et al. Perinatal exposure to bisphenol a alters early adipogenesis in the rat. Environ Health Perspect. 2009;117(10):1549-55. doi:10.1289/ehp.11342.

41. Miyawaki J, Sakayama K, Kato H, Yamamoto H, Masuno H. Perinatal and postnatal exposure to bisphenol a increases adipose tissue mass and serum cholesterol level in mice. J Atheroscler Thromb. 2007; 14(5):245-52.

42. Valvi D, Casas M, Mendez MA, Ballesteros-Gómez A, Luque N, Rubio S, et al. Prenatal bisphenol a urine concentrations and early rapid growth and overweight risk in the offspring. Epidemiology. 2013;24(6):791-9. doi:10.1097/EDE.0b013e3182a67822.

43. Harley KG, Aguilar Schall R, Chevrier J, Tyler K, Aguirre H, Bradman A, et al. Prenatal and postnatal bisphenol a exposure and body mass index in childhood in the CHAMACOS cohort. Environ Health Perspect. 2013;121(4):514-20. 520e1-6.

44. Evans RM, Barish GD, Wang Y-X. PPARs and the complex journey to obesity. Nat Med. 2004;10(4):355-61. doi:10.1038/ nm1025.

45. Hurst CH, Waxman DJ. Activation of PPARalpha and PPARgamma by environmental phthalate monoesters. Toxicol Sci. 2003;74(2): 297-308. doi:10.1093/toxsci/kfg145.

46. Stahlhut RW, van Wijngaarden E, Dye TD, Cook S, Swan SH. Concentrations of urinary phthalate metabolites are associated with increased waist circumference and insulin resistance in adult U.S. males. Environ Health Perspect. 2007;115(6):876-82. doi:10.1289/ ehp.9882.

47. Vanden Heuvel JP, Thompson JT, Frame SR, Gillies PJ. Differential activation of nuclear receptors by perfluorinated fatty acid analogs and natural fatty acids: a comparison of human, mouse, and rat peroxisome proliferator-activated receptoralpha, -beta, and -gamma, liver $X$ receptor-beta, and retinoid X receptor-alpha. Toxicol Sci. 2006;92(2):476-89. doi:10. 1093/toxsci/kfl014.

48. Seckl JR, Cleasby M, Nyirenda MJ. Glucocorticoids, 11betahydroxysteroid dehydrogenase, and fetal programming. Kidney Int. 2000;57(4):1412-7. doi:10.1046/j.1523-1755.2000.00984.x.

49. Nyirenda MJ, Lindsay RS, Kenyon CJ, Burchell A, Seckl JR. Glucocorticoid exposure in late gestation permanently programs rat hepatic phosphoenolpyruvate carboxykinase and glucocorticoid receptor expression and causes glucose intolerance in adult offspring. J Clin Invest. 1998;101(10):2174-81. doi:10.1172/ JCI1567.

50. Inadera H. Developmental origins of obesity and type 2 diabetes: molecular aspects and role of chemicals. Environ Health Prev Med. 2013;18(3):185-97. doi:10.1007/s12199-013-0328-8.

51. Muramatsu-Kato K, Itoh H, Kobayashi-Kohmura Y, Murakami H, Uchida T, Suzuki K, et al. Comparison between placental gene expression of 11 beta-hydroxysteroid dehydrogenases and infantile growth at 10 months of age. J Obstet Gynaecol Res. 2013. doi:10. 1111/jog.12200.

52. Ma X, Lian QQ, Dong Q, Ge RS. Environmental inhibitors of 11 beta-hydroxysteroid dehydrogenase type 2. Toxicology. 2011;285(3):83-9. doi:10.1016/j.tox.2011.04.007.

53. Legler J. Epigenetics: an emerging field in environmental toxicology. Integr Environ Assess Manag. 2010;6(2):314-5. doi:10.1002/ieam.40.

54. Ruchat S-M, Hivert M-F, Bouchard L. Epigenetic programming of obesity and diabetes by in utero exposure to gestational diabetes mellitus. Nutr Rev. 2013;71 Suppl 1:S88-94. doi:10.1111/nure. 12057.
55. Janesick A, Blumberg B. Obesogens, stem cells and the developmental programming of obesity. Int J Androl. 2012;35(3):437-48. doi:10.1111/j.1365-2605.2012.01247.x.

56. Skinner MK, Manikkam M, Guerrero-Bosagna C. Epigenetic transgenerational actions of endocrine disruptors. Reprod Toxicol. 2011;31(3):337-43. doi:10.1016/j.reprotox.2010.10.012.

57. Rosenfeld CS, Sieli PT, Warzak DA, Ellersieck MR, Pennington KA, Roberts RM. Maternal exposure to bisphenol A and genistein has minimal effect on $\mathrm{A}(\mathrm{vy}) / \mathrm{a}$ offspring coat color but favors birth of agouti over nonagouti mice. Proc Natl Acad Sci U S A. 2013;110(2):537-42. doi:10.1073/pnas.1220230110.

58. Dolinoy DC, Huang D, Jirtle RL. Maternal nutrient supplementation counteracts bisphenol A-induced DNA hypomethylation in early development. Proc Natl Acad Sci U S A. 2007;104(32): 13056-61. doi:10.1073/pnas.0703739104.

59. Li S, Washburn KA, Moore R, Uno T, Teng C, Newbold RR, et al. Developmental exposure to diethylstilbestrol elicits demethylation of estrogen-responsive lactoferrin gene in mouse uterus. Cancer Res. 1997;57(19):4356-9.

60. Wu Q, Ohsako S, Ishimura R, Suzuki JS, Tohyama C. Exposure of mouse preimplantation embryos to 2,3,7,8-tetrachlorodibenzo-pdioxin (TCDD) alters the methylation status of imprinted genes H19 and Igf2. Biol Reprod. 2004;70(6):1790-7. doi:10.1095/ biolreprod.103.025387.

61. Bernal AJ, Jirtle RL. Epigenomic disruption: the effects of early developmental exposures. Birth Defects Res A Clin Mol Teratol. 2010;88(10):938-44. doi:10.1002/bdra.20685.

62. Byun HM, Nordio F, Coull BA, Tarantini L, Hou L, Bonzini M, et al. Temporal stability of epigenetic markers: sequence characteristics and predictors of short-term DNA methylation variations. PLoS ONE. 2012;7(6):e39220. doi:10.1371/journal.pone. 0039220.

63. Langevin SM, Kelsey KT. The fate is not always written in the genes: epigenomics in epidemiologic studies. Environ Mol Mutagen. 2013;54(7):533-41. doi:10.1002/em.21762. This review descibes the application of epigenetic technology in epidemiologic studies and describes important considerations for utilizing this technology in epidemiologic research.

64. Bradman A, Whyatt RM. Characterizing exposures to nonpersistent pesticides during pregnancy and early childhood in the National Children's Study: a review of monitoring and measurement methodologies. Environ Health Perspect. 2005;113(8):1092-9.

65. Ozkaynak H, Whyatt RM, Needham LL, Akland G, Quackenboss J. Exposure assessment implications for the design and implementation of the National Children's Study. Environ Health Perspect. 2005;113(8):1108-15.

66. Faupel-Badger JM, Hsieh C-C, Troisi R, Lagiou P, Potischman N. Plasma volume expansion in pregnancy: implications for biomarkers in population studies. Cancer Epidemiol Biomarkers Prev. 2007;16(9):1720-3. doi:10.1158/1055-9965.EPI-07-0311.

67. Delano K, Koren G. Emerging biomarkers of intrauterine neonatal and pediatric exposures to xenobiotics. Pediatr Clin N Am. 2012;59(5):1059-70. doi:10.1016/j.pcl.2012.07.005.

68. Arora M, Austin C. Teeth as a biomarker of past chemical exposure. Curr Opin Pediatr. 2013;25(2):261-7. doi:10.1097/MOP. 0b013e32835e9084.

69. Glynn A, Aune M, Darnerud PO, Cnattingius S, Bjerselius R, Becker W et al. Determinants of serum concentrations of organochlorine compounds in Swedish pregnant women: a cross-sectional study. Environ Health. 2007;6. doi:10.1186/ 1476-069X-6-2.

70. Verner M-A, McDougall R, Glynn A, Andersen ME, Clewell HJ, Longnecker MP. Is the relationship between prenatal exposure to PCB-153 and decreased birth weight attributable to pharmacokinetics? Environ Health Perspect. 2013;121(10):1219-24. doi:10. 1289/ehp.1206457. 
71. Li D, Longnecker MP, Dunson DB. Lipid adjustment for chemical exposures: accounting for concomitant variables. Epidemiology. 2013;24(6):921-8. doi:10.1097/EDE.0b013e3182a671e4.

72. Schisterman EF, Whitcomb BW, Louis GMB, Louis TA. Lipid adjustment in the analysis of environmental contaminants and human health risks. Environ Health Perspect. 2005;113(7):853-7.

73. Johns DO, Stanek LW, Walker K, Benromdhane S, Hubbell B, Ross $\mathrm{M}$, et al. Practical advancement of multipollutant scientific and risk assessment approaches for ambient air pollution. Environ Health Perspect. 2012;120(9):1238-42. doi:10.1289/ehp.1204939.

74. Carlin DJ, Rider CV, Woychik R, Birnbaum LS. Unraveling the health effects of environmental mixtures: an NIEHS priority. Environ Health Perspect. 2013;121(1):A6-8.

75. Pajunen P, Kotronen A, Korpi-Hyövälti E, KeinänenKiukaanniemi S, Oksa H, Niskanen L, et al. Metabolically healthy and unhealthy obesity phenotypes in the general population: the FIN-D2D Survey. BMC Public Health. 2011;11:754. doi:10.1186/1471-2458-11-754.

76. Lausten-Thomsen U, Bille DS, Nässlund I, Folskov L, Larsen T, Holm J-C. Neonatal anthropometrics and correlation to childhood obesity-data from the Danish Children's Obesity Clinic. Eur J Pediatr. 2013;172(6):747-51. doi:10.1007/s00431-013-1949-z.

77. Wells JCK. Body composition in infants: evidence for developmental programming and techniques for measurement. Rev Endocr Metab Disord. 2012;13(2):93-101. doi:10.1007/s11154012-9213-9. This article reviews strategies for measuring body composition in infants and children in varied settings and presents a theoretical model describing how such data may be used to study later chronic disease.

78. Freedland ES. Role of a critical visceral adipose tissue threshold (CVATT) in metabolic syndrome: implications for controlling dietary carbohydrates: a review. Nutr Metab (Lond). 2004;1(1). doi:10.1186/1743-7075-1-12.

79. Murphy MJ, Metcalf BS, Jeffery AN, Voss LD, Wilkin TJ. Does lean rather than fat mass provide the link between birth weight, BMI, and metabolic risk? EarlyBird 23. Pediatr Diabetes. 2006;7(4):211-4. doi:10.1111/j.1399-5448.2006.00180.x.

80. Ibrahim MM. Subcutaneous and visceral adipose tissue: structural and functional differences. Obes Rev. 2010;11(1):11-8. doi:10. 1111/j.1467-789X.2009.00623.x.

81. McMillen IC, Robinson JS. Developmental origins of the metabolic syndrome: prediction, plasticity, and programming. Physiol Rev. 2005;85(2):571-633. doi:10.1152/physrev.00053.2003.

82. Shen W, Liu H, Punyanitya M, Chen J, Heymsfield SB. Pediatric obesity phenotyping by magnetic resonance methods. Curr Opin Clin Nutr Metab Care. 2005;8(6):595-601.

83. Binkovitz LA, Henwood MJ. Pediatric DXA: technique and interpretation. Pediatr Radiol. 2007;37(1):21-31. doi:10.1007/ s00247-006-0153-y.

84. Deierlein AL, Thornton J, Hull H, Paley C, Gallagher D. An anthropometric model to estimate neonatal fat mass using air displacement plethysmography. Nutr Metab (Lond). 2012;9:21. doi:10.1186/1743-7075-9-21.

85. Nassis GP, Sidossis LS. Methods for assessing body composition, cardiovascular and metabolic function in children and adolescents: implications for exercise studies. Curr Opin Clin Nutr Metab Care. 2006;9(5):560-7. doi:10.1097/01.mco.0000241665.38385.5b.

86. Wells JCK, Fewtrell MS. Measuring body composition. Arch Dis Child. 2006;91(7):612-7. doi:10.1136/adc.2005.085522.

87. Schmelzle HR, Fusch C. Body fat in neonates and young infants: validation of skinfold thickness versus dual-energy X-ray absorptiometry. Am J Clin Nutr. 2002;76(5):1096-100.
88. Meller M, Qiu C, Vadachkoria S, Abetew DF, Luthy DA, Williams MA. Changes in placental adipocytokine gene expression associated with gestational diabetes mellitus. Physiol Res. 2006;55(5):501-12.

89. Levy-Marchal C, Arslanian S, Cutfield W, Sinaiko A, Druet C, Marcovecchio ML, et al. Insulin resistance in children: consensus, perspective, and future directions. J Clin Endocrinol Metab. 2010;95(12):5189-98. doi:10.1210/jc.2010-1047.

90. Muniyappa R, Lee S, Chen H, Quon MJ. Current approaches for assessing insulin sensitivity and resistance in vivo: advantages, limitations, and appropriate usage. Am J Physiol Endocrinol Metab. 2008;294(1):E15-26. doi:10.1152/ajpendo. 00645.2007.

91. Halpern CT, Whitsel EA, Wagner B, Harris KM. Challenges of measuring diurnal cortisol concentrations in a large populationbased field study. Psychoneuroendocrinology. 2012;37(4):499508. doi:10.1016/j.psyneuen.2011.07.019.

92. Matthews K, Schwartz J, Cohen S, Seeman T. Diurnal cortisol decline is related to coronary calcification: CARDIA study. Psychosom Med. 2006;68(5):657-61. doi:10.1097/01.psy. 0000244071.42939.0e.

93. Bolten MI, Wurmser H, Buske-Kirschbaum A, Papousek M, Pirke $\mathrm{KM}$, Hellhammer D. Cortisol levels in pregnancy as a psychobiological predictor for birth weight. Arch Women's Mental Health. 2011;14(1):33-41. doi:10.1007/s00737-010-0183-1.

94. Steenland K. Marginal structural models to control for timevarying confounding in occupational and environmental epidemiology. Occup Environ Med. 2013;70(9):601-2. doi:10.1136/ oemed-2013-101629.

95. VanderWeele TJ. Invited commentary: structural equation models and epidemiologic analysis. Am J Epidemiol. 2012;176(7):60812. doi:10.1093/aje/kws213.

96. Sharpe RM, Drake AJ. Obesogens and obesity-an alternative view? Obesity (Silver Spring). 2013;21(6):1081-3. doi:10.1002/ oby. 20373 .

97. Rudel RA, Gray JM, Engel CL, Rawsthorne TW, Dodson RE, Ackerman JM, et al. Food packaging and bisphenol A and bis(2ethyhexyl) phthalate exposure: findings from a dietary intervention. Environ Health Perspect. 2011;119(7):914-20. doi:10.1289/ ehp. 1003170.

98. Rickman JC, Bruhn CM, Barrett DM. Nutritional comparison of fresh, frozen, and canned fruits and vegetables II. Vitamin A and carotenoids, vitamin E, minerals and fiber. J Sci Food Agric. 2007;87(7):1185-96. doi:10.1002/jsfa.2824.

99. Sato A. Confounding factors in biological monitoring of exposure to organic solvents. Int Arch Occup Environ Health. 1993;65(1 Suppl):S61-7.

100. Baxmann AC, Ahmed MS, Marques NC, Menon VB, Pereira AB, Kirsztajn GM, et al. Influence of muscle mass and physical activity on serum and urinary creatinine and serum cystatin C. Clin J Am Soc Nephrol. 2008;3(2):348-54. doi:10.2215/ CJN.02870707.

101. Boeniger MF. Interpretation of urine results used to assess chemical exposure with emphasis on creatinine adjustments: a review. Am Ind Hyg Assoc J. 1993;54(10):615-27.

102. Lindsay AR, Hongu N, Spears K, Idris R, Dyrek A, Manore MM. Field assessments for obesity prevention in children and adults: physical activity, fitness, and body composition. J Nutr Educ Behav. 2013. doi:10.1016/j.jneb.2013.03.013.

103. Wells JCK. Sexual dimorphism of body composition. Best Pract Res Clin Endocrinol Metab. 2007;21(3):415-30. doi:10.1016/j. beem.2007.04.007. 